Article

\title{
Industrial Symbiosis in the Upper Valley: A Study of the Casella-Hypertherm Recycling Partnership
}

\author{
Jonathan S. Krones
}

School of Forestry and Environmental Studies, Yale University, New Haven, CT 06511, USA; jonathan.krones@yale.edu; Tel.: +1-301-788-4206

Academic Editor: Marc A. Rosen

Received: 1 April 2017; Accepted: 10 May 2017; Published: 12 May 2017

\begin{abstract}
The Casella-Hypertherm Recycling Partnership (CHRP) is a collaboration between a waste management company and a manufacturer that has created a unique recycling environment for companies in the Upper Valley region of Vermont and New Hampshire. This article presents the CHRP as a novel form of industrial symbiosis (IS) using the recently published theoretical framework of IS dynamics proposed by Boons et al. We present this partnership in the academic literature for the first time and also gauge the adequacy of the typology when faced with a new model of IS. We argue that the CHRP exhibits qualities of multiple dynamics, and may in fact be an example of a new dynamic which we call "active facilitation". Finally, the article also contributes evidence to the Boons et al. generative research question about the relationship between initial conditions and specific dynamics by analyzing the context in which the CHRP emerged.
\end{abstract}

Keywords: industrial symbiosis; resource management; corporate sustainability; recycling; partnerships; New England; case study

\section{Introduction}

For decades, concerns about environmental degradation and natural resource scarcity have motivated academics, businesses, and policymakers to explore new ways of satisfying society's growing material and economic needs that are fundamentally more sustainable —or at least more resource-efficient and less environmentally impactful—than the status quo. One of the models that has emerged is that of industrial symbiosis (IS), a phenomenon of multi-actor coordination of waste utilization and resource efficiency for both mutual and system-wide economic and environmental benefit. Over the years, IS has been considered as, alternatively, an academic field of study [1], a strategy for private sector competitive advantage [2], a public sector eco-industrial policy priority [3], an idealistic vision for sustainability activism [4] and, at times, all of the above.

The interplay between academic scholarship and real-world implementation of IS has been vital to the development and deployment of the concept. Following the initial recognition of pioneering eco-industrial parks like that in Kalundborg, Denmark, industrial ecologists and other researchers responded mainly through detailed case studies, calculating the coupled environmental and economic benefits realized by the parks and identifying characteristics that seemed to be key to their success [5-8]. The results of this research enabled scholars to draw generalized, if still rudimentary, conclusions about IS that could then be used prescriptively by businesses and coordinating bodies like governments and brokers to attempt to replicate past successes. These subsequent attempts, both successful and not, could then serve as fodder for new research, feeding a cycle of refinement of both theory and practice.

In addition, the process of essentialization has served to decouple the concept from the relatively small set of initial observations, enabling the research community to explore IS in a broader universe of examples. After all, inter-firm recycling linkages are nothing new; on the contrary, "the practice of 
turning byproducts into the valuable inputs of another industry is as ancient as economic development" itself ([9], p. 1035). Neither is it a boutique or infrequent occurrence, as examples of highly complex, multi-actor networks of waste reuse and recycling can be (and have been) "uncovered" in urban and industrial areas worldwide $[10,11]$. Whether or not these networks are recognizable as IS, however, is debatable, and depends in part on the state of IS theory, which until recently had been in early stages of development.

In 2016, Boons et al. [12] took a large step forward in the process of scholarly convergence by proposing a typological theory of IS dynamics and a framework that links together initial conditions, dynamics, and observed outcomes. Rather than claiming the final word on the subject, the authors, who include leading IS scholars from around the world, took the opportunity to explicitly invite the broader research community to critique their typology and engage in collaborative theory building using their framework as a starting point. Here, we respond to this invitation by presenting a case study of the Casella-Hypertherm Recycling Partnership (CHRP), a collaboration between a solid waste resource management company and a manufacturer that has created a unique recycling environment for companies in the Upper Valley region of Vermont and New Hampshire.

The CHRP has received a modest amount of attention since it began operations in January 2015, including a 2016 "Partnerships for Innovation" award from the New Hampshire Businesses for Social Responsibility (NHBSR) [13]. Despite not resembling the eco-industrial parks of IS past, the CHRP can nonetheless be understood to be a novel form of IS, especially when examined using Boons et al.'s vocabulary of IS dynamics. Furthermore, because the CHRP was not known to Boons et al. and seems to be functionally and structurally distinct from any of the foundational examples that contributed to the development of the typology, it serves as a valuable test case for evaluating the adequacy of relevant individual dynamics as well as the sufficiency of the set as a whole. This article also offers evidence for two of the three generative research questions proposed by Boons et al.: "Are different dynamics triggered under specific conditions?" and "How do dynamics add up into phase models?" ([12], pp. 9,11). The third question, "What outcomes are linked to different types of dynamics?" is not addressed here in part because of the newness of the CHRP.

Beyond the scholarly objectives of offering a critique of the IS dynamics typology and contributing to a collaborative research agenda, this research project also has practical goals. The CHRP is an innovative inter-firm arrangement, and whether or not it ends up entering the IS canon, its uniqueness alone makes it deserving of academic attention. The descriptive and analytical treatments offered in this case study expose an organizational model that others interested in improving resource efficiency may find inspirational or even directly applicable. Finally, an external perspective such as an academic case study can be helpful for the subject organization itself, which may be limited in its frame of reference. By positioning the partnership as a form of IS, it is given a new set of peers to which its leadership may now be able to look.

The structure of this article is as follows: The next section describes the approach we took to data collection and construction of the case study. This is followed by background information on the geographic context and key actors of the CHRP in Section 3. Sections 4 and 5 describe the development and operation of the CHRP, first in narrative form, then using the Boons et al. typology of IS dynamics. The article closes with a discussion of the adequacy and sufficiency of the typology, the contributions of this case study to the aforementioned collaborative research agenda, and a summary of conclusions.

\section{Data Sources}

The development and analysis of this case study relied on both qualitative and quantitative data. In November 2016, interviews were conducted with nine individuals-five from Casella and four from Hypertherm - all of whom had been involved with the partnership in some capacity and whose different roles offer distinct perspectives on its evolution and operation. The five Casella interviewees occupy positions throughout the company's organizational chart, including the partnership facility on-site manager, the Hypertherm contract and account managers, the Casella sustainability director, 
and the senior vice president overseeing the Casella Resource Solutions professional services business. The Hypertherm interviews targeted the team directly involved with and responsible for the company's extensive waste reduction efforts, including two dedicated environmental program managers, a facilities manager, and the vice president of corporate social responsibility.

Following these interviews, partnership staff provided data on sources and quantities of waste materials handled at the facility. This was enriched throughout the research process with other publicly available information about the key partners and partnership, including news articles and annual corporate and sustainability reports.

\section{Background}

An essential element of the Boons et al. theory and research agenda is the relationship between the observed IS dynamic and its underlying context. To establish this context, this section presents background information about the historical, technical, economic, geospatial, social, and institutional conditions in which the CHRP emerged.

\subsection{Upper Valley}

\subsubsection{Geography and History}

The "Upper Valley" is a region of New Hampshire (NH) and Vermont (VT) alongside a $70 \mathrm{~km}$ stretch of the Connecticut River, which defines much of the border between those two states in the Northeast United States. Despite its relative inaccessibility, European settlers were first drawn to the fertile agricultural soil and abundant natural resources of the Connecticut River Valley in the mid- to late-17th century [14]. The first industries to emerge in the region were intimately tied to its natural endowments: forestry and logging, the products of which would be transported to population centers down-river in famous log-drives; and agriculture. According to Beihl ([14], p. 22), "By the late eighteenth century, the upper Connecticut River Valley became a sort of paradox: on one hand, it was a frontier society based on the agricultural goods that it produced for urban centers; on the other hand, its newfound resources and accessibility allowed it to become a place that generated culture and supported commercial endeavors, much like an urban development."

Water-powered mills, which had become commonplace throughout New England by the turn of the 19th century, including elsewhere in the Connecticut River Valley, were slow to arrive in the Upper Valley. Easy access to mills and markets provided by transport on the Connecticut River allowed the region to maintain its agrarian roots, with manufacturing occurring mainly in small-scale craft and artisanal production, although water-powered sawmills would become increasingly common [14]. Sawmills were followed by grist and textile mills, the latter finding no shortage of wool to process in towns like Hartford, VT, and Lebanon, NH, which by 1840 each had more than six times as many sheep as people [15]!

During the industrial revolution, inventors and companies in the Upper Valley made significant contributions to the development of precision manufacturing, with factories in Windsor, VT mass-producing rifles with interchangeable parts as early as the mid-1840s [16]. Tool and machine shops soon spread throughout the region, and new road and rail connections opened up the national market to these and other companies. Paper manufacturing also became a major industry in the latter part of the 19th century, after chemical pulping technology was developed to create paper out of wood [17]. From their peak in the first half of the 20th century, these industries declined rapidly after about 1950, casualties of the modern economy.

\subsubsection{The Upper Valley Today}

Today, much of the Upper Valley region is within the Lebanon, NH-VT Micropolitan New England City and Town Statistical Area (Micro-NECTA), a geo-demographic designation by the U.S. Office of Management and Budget of 29 towns and small cities across roughly $3000 \mathrm{~km}^{2}$ centered on Hanover 
and Lebanon, NH, and Hartford and Norwich, VT [18]. The definition and boundaries of each Micro-NECTA are determined by a "central urban core, plus adjacent outlying villages and towns having a high degree of social and economic integration with the central urban core as measured through commuting trips" ([18], p. 6). In this case, the primary city is Lebanon, NH, with a 2015 population of 13,500 out of a total Micro-NECTA population of about 84,000 , split $56 \% / 44 \%$ between New Hampshire and Vermont, respectively [19]. Since the boundaries of the statistical area were first defined after the 2000 U.S. Census, it has grown steadily, from 25 towns in 2000 to 29 in 2015, and increasingly the Lebanon Micro-NECTA is being superseded by the even larger Claremont-Lebanon, NH-VT Combined NECTA, indicating a growing degree of integration in the region.

The largest industries in the Upper Valley today are healthcare and education, represented by the Dartmouth-Hitchcock Medical Center in Lebanon and Dartmouth College in Hanover. Together, these sectors provide nearly $40 \%$ of the jobs in the Upper Valley [20]. Professional services are responsible for $10 \%$ and retail trade for $9 \%$, with another $9 \%$ provided by the manufacturing sector. The manufacturing sector in the Upper Valley is highly diversified. Among the roughly 350 manufacturing establishments, $28 \%$ are involved in equipment and tool manufacturing, $15 \%$ in wood products manufacturing, and $8.5 \%$ in food processing, with the balance distributed across the spectrum of industrial codes [21]. These establishments are also small, for the most part, with $60 \%$ having fewer than 10 employees and only $7 \%$ having more than 100 employees. One effect of the large education, health care, and specialty manufacturing sectors is that residents of the Upper Valley tend to be well-educated, with above-average median incomes [22].

The regional integration of the Upper Valley, both internally and throughout New England, is facilitated by the presence of two interstate highways: Interstates 89 and 91, which intersect near the midpoint of the Upper Valley. I-89 proceeds southeast towards the Boston area, while I-91 largely parallels the Connecticut River south through Springfield, Massachusetts and Hartford, Connecticut, terminating at I-95 in New Haven, Connecticut.

\subsection{Casella Waste Systems}

Casella Waste Systems, Inc. is a publicly-traded solid waste resource management company based in Rutland, Vermont, that operates primarily, although not exclusively, in the Northeast United States. Founded in the mid-1970's as a single-truck hauling operation, Casella has grown organically and through acquisition to become a major regional, integrated waste management service provider, with collection, transfer, disposal, and recycling operations serving residential, commercial, industrial, institutional, and municipal clients. As of 2016, Casella owned or operated 10 landfills, eight large material recovery facilities, 44 transfer stations, and numerous collection operations throughout the region [23]. Collection and disposal remain Casella's core businesses, responsible for $44 \%$ and $29 \%$ of their FY2015 revenues, respectively. An additional one quarter of revenues come from what Casella calls their "value-added resource solutions", including recycling, organics (e.g., food scraps) management, and "customer solutions" (professional services) [23]. Despite being comparatively smaller operations, Casella has demonstrated a commitment to continual technological and business model innovation in their resource solutions businesses and backed this up with capital investment. Casella leadership sees these businesses not just as important market differentiators but also as providing synergistic benefits across the company.

Casella's Customer Solutions business provides professional services to large industrial, institutional, and commercial clients, and is the only business unit of the company to have a significant footprint outside of the Northeast U.S. Historically, this business operated with a brokerage model, whereby Casella would simply facilitate the sale of, for example, large quantities of recyclable materials from a manufacturing operation [23]. In recent years, however, Customer Solutions has evolved into a professional waste and materials management services provider focusing on large industrial and institutional customers, analogous to private security or food service providers. This transition has 
occurred in a large part due to the influence of Paul Ligon, the senior vice president of development and strategy for Casella.

Ligon came to Casella with considerable expertise with a type of contract between waste generators and solid waste contractors known as "resource management" (RM), in which "contracts are structured to decouple the quantity of waste disposed from the contractor's profit by providing financial incentives for services related to material consumption, use and recovery" ([24], p. 51). RM can be thought of as a waste and materials analogue [25] to other environmental performance-based business models like energy service companies (ESCOs) [26] and product-service systems [27]. As a senior scientist at the Tellus Institute in the 1990s, Ligon had conducted research into RM contracting, proposing specific mechanisms by which strategic contracting could lead to decreased costs, increased revenues, and improved environmental outcomes [24,28]. He then had the opportunity to put his theories into practice at Waste Management, Inc.'s Upstream Division before joining Casella in 2012.

The transformation of the Customer Solutions business from a brokerage model to a RM model was accelerated with the acquisition of the environmental services and consulting firm A Greener Solution (AGS) in 2013. AGS had been managing recycling programs for numerous large industrial and commercial companies for many years, and brought to Casella real-world expertise in writing and executing various types of RM contracts. Additionally, as a Midwestern company, the AGS acquisition expanded Casella's base of potential clients and vendors.

Casella is not alone in the RM and industrial waste management professional services market. It competes with industry giants (e.g., Waste Management) and hazardous waste management firms (e.g., Stericycle and Clean Harbors) as well as new entrants, including IT-enabled brokers (e.g., Rubicon) and business consultants (e.g., Accenture). Casella occupies a middle ground compared with the established companies, which tend to be very asset-heavy (in terms of owning and operating disposal facilities), and the new entrants, which are often asset-light. Its collection, disposal, and recycling assets in the Northeast give it the experience of physically handling waste and the competitive advantage of vertical integration, but the regionality of these assets also provides Casella with a degree of agility often associated with the asset-light firms.

In practice, the RM contract model authorizes Casella to not only be responsible for transporting material off of a client's site, but also to take over the client's internal waste handling operations, so that the material that ends up at the loading dock is in a better position to be recycled or disposed of in a more economically and environmentally beneficial way. For example, in their RM contract with Becton-Dickinson (BD), a global medical device company, Casella took over in-facility waste management operations, improving material tracking, sorting, and education [29]. This then allowed Casella to work with a broad network of processing and specialty recycling vendors, leading to a large increase in BD's waste diversion rate and decreased disposal costs. Once Casella staff were integrated into BD's operations, it also provided the opportunity to start work on even higher-value interventions, such as the development of a closed-loop recycling program for production waste plastics. With each successful contract, Casella both builds its management capacity for more and different types of RM programs and further develops its valuable network of vendors.

\subsection{Hypertherm}

Hypertherm is a world-leading manufacturer of industrial cutting tools based in Lebanon, $\mathrm{NH}$. The company was founded in 1968 to commercialize an innovative plasma cutting process invented by founders Dick Couch and Bob Dean. Today, all of Hypertherm's plasma, waterjet, and laser cutting tools are still manufactured in Hanover and Lebanon, $\mathrm{NH}$, and exported around the world for use in construction, shipbuilding, vehicle manufacturing, mining, and every other industry with metal cutting needs. The current Hypertherm mission statement is "to provide customers with the world's leading industrial cutting solutions, to promote the well-being and development of our Associates, and to enrich our communities and environment" [30]. Each of these three pillars is taken seriously 
and receives considerable attention by people throughout the organization, and in practice they tend to reinforce one another.

In service of the first goal of its mission statement, Hypertherm embraces Lean Six Sigma, which contributes to a high-quality, well-controlled manufacturing environment. Lean principles can be observed throughout the company, for example in the cross-functional teams that are employed in a variety of contexts such as continuous improvement and safety. The systematic drive to minimize waste that is at the core of the lean philosophy leads to an acute awareness of the sources-both direct and indirect-of production costs, a type of applied systems thinking that facilitates the deployment of innovative solutions. The physical layout of the factory also reflects lean principles, with the space organized according to the $5 \mathrm{~S}$ methodology, prioritizing clarity, cleanliness, and organization. Internally, work stations are expected to pass the "visitor test," in which any employee should be able to walk up to any station and understand the work flow, even if they cannot necessarily perform every individual task. This means that everything is well-labeled and has a dedicated and accessible place, with consistent visual guidelines across the factory.

The second goal concerns the "well-being and development of [the] Associates". Today, Hypertherm is a $100 \%$ employee-owned company through an Employee Stock Ownership Plan (ESOP). For this reason, employees are referred to as "associates" or "associate-owners". Although the ESOP is a relatively new development, a profit-sharing plan was created shortly after the founding of the company, and has paid out every year since the early 1980s, even when the CEO had to pay out bonuses personally [31]. The ESOP was created in 2001 with $30 \%$ of the company's shares, increasing to $100 \%$ in 2014 [32]. Distinct from a cooperative, the ESOP gives the associates ownership but not control of Hypertherm, which remains with a traditional corporate leadership team, including the founder and former CEO Dick Couch (who is also the trustee of the ESOP).

A commitment to the wellbeing of the associates goes beyond shared ownership. According to Koller ([31], p. 185), "Over four decades, the [Hyperthem] workforce has expanded to more than 1000 permanent workers-and no one has ever been laid off for economic reasons." This policy, along with the ESOP, has contributed to a culture of loyalty and trust at the company, with associates demonstrating a willingness to collectively work fewer hours during difficult economic times to maintain the no-layoff policy [31].

Hypertherm's corporate social responsibility (CSR) goals also find their origins in the founding values of the company, which included a "balanced approach to a workforce, the shareholders, and the community" ([31], p. 189). Early CSR activities were focused mainly on community engagement and philanthropy; since 2003 Hypertherm has been giving associates days off with pay to perform community service [33]. In 2010, the company began an effort to more explicitly include environmental stewardship in its CSR portfolio by developing goals for environmentally sustainable manufacturing and operations. A year-long environmental audit produced a dashboard that focused on greenhouse gas emissions, energy efficiency, and solid waste generation in three areas: products, logistics, and business operations, including manufacturing. Although the largest environmental impacts were found to be the energy consumption (and associated emissions) of the installed product base, logistics, and manufacturing, waste from business operations was also selected for two main reasons. First, as a lean enterprise, Hypertherm was already well-positioned to eliminate unnecessary waste of inventory, movement, etc., and solid waste minimization is a natural next step. Second, although recycling is not the most environmentally impactful action a manufacturing company can take, it is a very tangible way to engage and mobilize an organization and community around environmental values.

The waste goals were framed in terms of targets for 2020: make $100 \%$ of manufactured products recyclable, reusable, or properly reclaimed at the end of their lives; reduce packaging by $30 \%$ and ensure all outbound packaging material is recyclable; and achieve zero waste from business operations [33]. Hypertherm had experience managing some of their wastes for recycling; large amounts of waste copper and brass are produced in their manufacturing processes, much of which was already recovered 
and sold as scrap. Nevertheless, Hypertherm associates estimate that they still disposed of 191 metric tons of waste, or $42 \%$ of total non-metallic waste generated (14\% of total waste generated), in 2010 [33].

The strategies for meeting these targets have taken multiple forms. To engage the associate base, a Green Champions program was set up, which facilitates bottom-up innovation and dissemination of best practices. Teams within the company perform waste audits and are given support to reduce and recycle waste through product and process design, although in one case a large amount of paper waste was avoided simply through reinstalling printer drivers. The culture of lean manufacturing and cost awareness has been vital, as it enables the teams to make systems-level arguments for waste reduction investments. For example, Hypertherm recently hired two packaging engineers to design robust, returnable packages for its inbound materials, justifying the hire based on an internal audit that revealed nearly 10 full-time equivalents dedicated solely to opening and handling single-use packages.

The company's leadership has also demonstrated a willingness to make large, long-term investments to meet its waste goals. Oil is used as a lubricant and a coolant in the copper-cutting systems in the factory, and in so doing picks up a large quantity of metal chips and dust. Any oil-metal mixture must be disposed of as hazardous waste, so Hypertherm installed a cleaning system that separates the copper from the oil, allowing the former to be recycled and the latter to be reused, and avoiding nearly all of the hazardous waste generation (less than one drum in four years). Although the system works well, it is expected to have a 20-year payback period, which reflects both the values-driven decision-making and long-term vision of the company.

When properly accounted, waste reduction often translates into financial savings, and since Hypertherm is associate-owned, there is a built-in incentive for associates to participate in waste reduction activities and propose new ideas, since they will realize the savings come profit sharing time. In this way, the three goals of Hypertherm's mission have been working synergistically in pursuit of the zero-waste goal. By 2014, disposed waste was down to 98 metric tons, and due to the growth in production from 2010 to 2014 , that represents just $18 \%$ of non-metal waste and $4.4 \%$ of total waste generation [33].

\section{Casella-Hypertherm Recycling Partnership}

\subsection{Development of the Partnership}

The CHRP first began accepting material in January 2015, but the process of developing the partnership started five years earlier. While they were first establishing their environmental goals in 2010, a group of Hypertherm associates visited the Subaru of Indiana factory in Lafayette, Indiana to learn about manufacturing sustainability best practices. They observed that Subaru had contracted with a materials management service provider who developed detailed waste statistics and disaggregated reduction targets, and provided financial incentives and disincentives to the employees to reach their goals. This level of sophistication resonated with Hypertherm's lean manufacturing sensibilities, as did the fact that Subaru was able to make money from selling its recyclable wastes.

Casella had been providing Hypertherm with waste collection services since 1996, when they inherited the Hypertherm contract in an acquisition. In 2012, Hypertherm approached their contract manager to see if Casella would be able to provide a service similar to that which the Hypertherm team observed in Indiana. At the time, Casella was just starting to develop its resource management business, not yet having acquired A Greener Solution, and Hypertherm's request was outside the capabilities of the collection division. Miscommunications between the two companies almost scuttled the partnership before it even began. Hypertherm, despite being a global leader in cutting tools, generates only a moderately small amount of waste, even by Upper Valley standards. The Casella collection division, which also serviced much larger generators like hospitals, did not fully appreciate why a small generator would be interested in such an involved intervention for what was, in their eyes, at best a marginal reduction in tonnage. Hypertherm similarly did not fully understand the realities of the recycling markets, which require a large minimum tonnage for entry to justify transportation 
and other transaction costs. Despite these misunderstandings, the relationship remained intact in part because both companies are members of the NHBSR, and at one of their events, Hypertherm's then-Director (now VP) of Corporate Social Responsibility mentioned her concerns to Casella's Sustainability Director, and the two were able to reopen lines of communication.

Discussions started up again in 2014, after Casella had acquired AGS and successfully executed other RM contracts around the country. Hypertherm had made considerable strides reducing waste from incoming packaging and their manufacturing processes, but still wanted a professional service provider to help them recycle the remaining wastes, which included conventional recyclables as well as small tonnage specialty materials. The main barrier, aside from working out the specific details of the contract structure, would be accumulating sufficient quantities of recyclable materials. The proposed solution to this problem was to create a cooperative model in which generators from around the Upper Valley would combine their wastes together to have enough material to sell on the recycling markets. This was distinct from any of the other RM models Casella had worked on, in which they were embedded solely in their customer's operations. The cooperative model would require some external facility for receiving, sorting, baling, and other types of materials handling. When Hypertherm offered space in an available warehouse for a pilot project, the CHRP was born.

\subsection{Operation of the Partnership}

The operation of the CHRP involves a number of related activities. Most prominently, Casella operates a facility in a Hypertherm warehouse in which recyclable materials from Hypertherm and other companies in the Upper Valley region are received, sorted, baled, stored, and shipped. Facility staff maintain detailed logs and provide a dashboard to Hypertherm managers to support their data-driven waste reduction goals. Additionally, like other, more traditional RM contracts, Casella staff also work with Hypertherm teams directly both to optimize material handling within their factories and to identify opportunities for waste reduction. Finally, Casella is also responsible for finding and qualifying vendors (reviewing their capabilities, permits, insurance, etc.) for the materials received at the CHRP, some of which are conventional recyclables while others require more creative solutions. Since the partnership facility opened in January 2015, it has been featured multiple times in local media outlets [34-36].

\subsubsection{Material Inflow}

In May 2015, the CHRP held an open house to showcase the operation to waste generating businesses in the region to try to source sufficient quantities of the hard-to-recycle materials. Hypertherm's positive reputation in the region attracted nearly two dozen interested businesses to the open house [34], and continues to be useful in convincing new partners to participate in the CHRP. After two years of operation, the CHRP now collects materials from 13 Hypertherm facilities and 10-20 other waste generators in and around the Upper Valley including Dartmouth-Hitchcock Medical Center, Cabot Creamery, GW Plastics, and King Arthur Flour [36]. CHRP staff are responsible for collecting materials from the Hypertherm facilities, while the third-party (non-Hypertherm) clients supply the CHRP in one of four ways: (1) they bring their own materials (drop-off); (2) their waste hauler (almost always a Casella collection contract) brings the loads to CHRP instead of a transfer station; (3) CHRP staff pick them up; or (4) a third-party logistics service brings material procured by Casella's sourcing team.

Many third-party clients do not observe any change in their recycling service, as the materials are simply delivered to the CHRP facility rather than to other recycling facilities or transfer stations. However, in some cases, the added local material handling capacity has opened up new recycling options for third parties, even if they do not have formal RM programs. So far, this has happened mainly in the case of non-rigid plastics like hospital blue wrap, shrink wrap, and plastic bags, which are excluded from most conventional recycling services. Having a local consolidator allows companies to remove these materials from their disposal streams, potentially decreasing their disposal costs. 
For companies that generate large volumes of plastic bags, diversion to the CHRP can eliminate entire days of trash hauling service. In the case of one of the hospitals, a team of nurses had been volunteering to collect, fold, package, and ship their used blue wrap for recycling. The CHRP enables them to now simply collect the materials in bags, saving them significant time and effort.

Figure 1 shows the distributions (by weight) of materials received and handled by the CHRP from January through October 2016. Figure 1a illustrates the distribution by material type of just those materials received from the 13 Hypertherm facilities. This includes all waste material generated by the company excluding most metal recycling, hazardous waste, recycled (composted) food waste, and any internal reuse. The data set includes conventional waste categories like zero-sort (Casella's trademarked term for fully commingled recycling, also known as single-stream) and trash, which gets sent to landfill. The small quantities of non-rigid and other specialty plastics, including proprietary thermosets, rubber, high-density polyethylene (HDPE), high-impact polystyrene (HIPS), and polypropylene (PP), is what motivated the expansion of the model to other Casella clients in the Upper Valley and beyond. Without increased volume, the CHRP would be unable to recycle those materials economically. As a result of ongoing, internal waste reduction activities and the CHRP, Hypertherm's 2015 disposed waste had declined to 43 metric tons (from 191 metric tons in 2010), less than $10 \%$ of the non-metal waste generated (2.2\% with metals) [33].

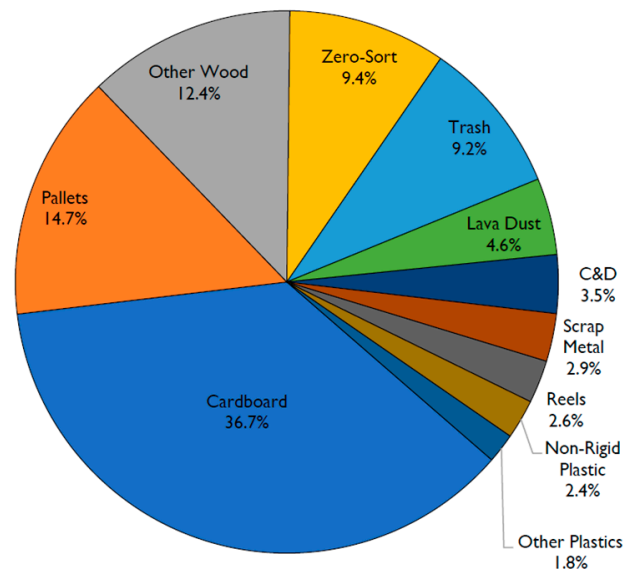

(a)

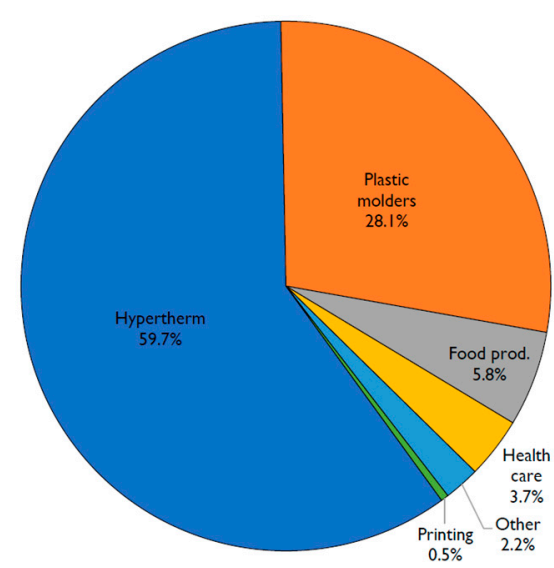

(b)

Figure 1. Materials received and processed by the CHRP, Jan-Oct 2016: (a) Distribution by weight of materials received from Hypertherm facilities, by material/product type; (b) Distribution by weight of materials received from all sources, by generator industry sector.

Figure $1 \mathrm{~b}$ illustrates the distribution by source of materials. Hypertherm-sourced materials are the largest fraction by far (nearly $60 \%$ of the total), followed by plastic molders, food producers like King Arthur Flour and Cabot, hospitals, and small amounts from elsewhere. The materials coming from the third-party facilities are primarily cardboard and non-rigid plastics, although the plastic molders also send rigid plastics. More conventional waste streams from third parties like commingled recycling and trash are not handled by the CHRP.

\subsubsection{Material Outflow}

After pre-processing, which may include sorting, shredding, and/or baling, not to mention stockpiling, materials handled at the CHRP facility are shipped out to one of three types of destinations: direct recycling, intermediate processing or brokerage, or reuse. For example, of the conventional materials, old corrugated cardboard is sold directly to a mill and plastics of all kinds are sent to a processor. In both of these cases, Lebanon, $\mathrm{NH}^{\prime}$ s interstate highway access was referenced by a Casella employee as being an important characteristic in minimizing costs. 
CHRP staff see what they do as a type of value-add manufacturing operation, keeping very good track of what comes in, keeping it clean and high quality, and selling it at the highest price they can manage. For new or unconventional waste types (reels, thermoset plastics, etc.), Casella works with Hypertherm to find environmentally beneficial uses. Used products like pallets and reels are technically able to be reused readily, and while the CHRP has found a vendor for used pallets, they have encountered some resistance when they attempted to sell used reels back to the wire and hose companies that sent them in the first place, despite the mutually favorable financials.

The proprietary thermoset plastic that Hypertherm uses in its plasma cutters also posed a challenge to Hypertherm's zero waste goals. As a process waste, it was easily collected, but as a thermoset it cannot be recycled in the same way as conventional thermoplastics. Before the CHRP was set up, a Hypertherm procurement officer, who was familiar with the markets for this particular polymer, found a buyer in the oil and gas industry who was interested in using the material, but that plan fell through when the price of petroleum declined. Recently, that same procurement officer found another buyer who is interested in purchasing large quantities of the waste thermoset material, so the $\mathrm{CHRP}$ is serving merely as a stockpiling location until they accumulate a quantity large enough to ship to this vendor.

The highly specialized nature of this material lends itself to Hyperthem taking the lead on identifying potential vendors, yet the process of creating such recycling linkages remains highly collaborative between the two companies. Even in the case of the thermoset polymer waste, Casella vetted potential partners using their well-tested vendor qualifying process, and continues to tap into their extensive network to find better and higher value opportunities for the material. For example, they have facilitated meetings between Hypertherm engineers and researchers from a plastics engineering department at a university that is another of Casella's customers in order to explore new ways to solve the recyclability problem of this challenging material.

\section{Typological Analysis}

Upon first glance, it is not obvious that the CHRP is an example of industrial symbiosis, especially since it is relatively small-scale and does not involve any traditional IS industries like refineries or power plants. However, considering IS as a process, and in particular the typology of IS dynamics presented by Boons et al., we argue that not only does the CHRP meet the criteria for IS, it in fact exhibits elements from four of the seven dynamic types. Each of the dynamics is characterized by Boons et al. ([12], p. 5) by "initial actors, their motivation, overall storyline, and typical outcomes." In this section, we restate the narrative of the CHRP presented above in the format of each of the four relevant dynamics: (1) self-organization, (2) organizational boundary change, (3) facilitation-brokerage, and (4) facilitation-collective learning. The remaining three, (5) pilot facilitation and dissemination, (6) government planning, and (7) eco-cluster development, do not appear to be relevant.

\subsection{Self-Organization}

"The dynamic of self-organization describes the development of symbiotic activities as a result of the self-motivated strategies of industrial actors" ([12], p. 6).

In this dynamic model, the initiator is an industrial actor motivated by "economic and/or environmental benefits from IS". Industrial actors are defined by Boons et al. as "the economically and organizationally discernible units (with some discretionary decision-making power) that undertake activities that transform inputs into outputs intended for further transformation or consumption" ([12], p. 4). The initiator of the CHRP could be argued to be either partner, but it is probably more accurate to imbue Hypertherm with this role both because as a manufacturer it is a more traditional industrial actor and because it was in fact the first motivated party.

In Boons et al., the overall storyline of each dynamic is given as a sequence of steps. Here (and in the subsequent subsections), each step is reproduced from the source reference ([12], p. 5), followed by its specific instantiation in the CHRP. 
(1) Industrial actors expect benefits in developing symbiotic linkages

Hypertherm, the initial actor, wants to reach its zero waste goals, which requires the development of reuse or recycling linkages for its waste materials.

(2) Industrial actors search for suitable partners $\rightarrow$ after finding a suitable partner, contracts are negotiated $\rightarrow$ linkage becomes operative

Hypertherm approaches Casella about developing a recycling partnership. After negotiation, the two companies form the CHRP, in which Hypertherm sends all of its recyclables to Casella.

(3) Repeat [1 and 2].

Casella/CHRP becomes the key actor, searching for both inbound and outbound linkages. Hypertherm continues to search for and implement linkages when it has more expertise than Casella, for example with its own suppliers or with some specialty materials.

Although there was and continues to be a great deal of self-organization involved with the CHRP, this model falls short of fully explaining the development dynamics of the partnership, partly because Casella does not quite meet the criteria of an "industrial actor" per the typology. In a practical sense, it is an industrial firm and, as discussed above, considers its resource management operations as a type of manufacturing process in terms of value addition, but its role in the CHRP extends beyond "transform[ing] inputs into outputs intended for further transformation or consumption." Instead, Casella actively facilitates the exchanges from Hypertherm and the other Upper Valley partners, through the CHRP, to vendors near and far. As we will see in the next few subsections, this activity may be better explained with a different type of dynamic.

\subsection{Organizational Boundary Change}

"The dynamic of organizational boundary change describes cases where symbiotic networks form and evolve when firms make changes in their organizational boundaries" ([12], p. 7).

For this dynamic, Hypertherm is again the initial industrial actor, motivated by "eco-efficiency and business strategy" as it pursues its waste reduction goals through its lean manufacturing framework.

(1) An industrial actor expands its activities through vertical integration and develops internal exchanges

Hypertherm vertically integrates its waste-related operations, including packaging design, improved source separation, and brokerage of recycling and reuse.

(2) The industrial actor changes its strategy from vertical integration into outsourcing

Hypertherm hires Casella to take over its waste and materials handling operations, resulting in the development of the CHRP.

(3) The linkages remain and the system evolves into an interorganizational network.

The stable relationship between Hypertherm, Casella, and the CHRP facility serves as the core of the symbiosis network.

As with the self-organization model, the organizational boundary change model only partially suits the CHRP. The main insufficiency of this dynamic is that neither Hypertherm nor Casella really develops its own internal exchanges to the extent of, for example, a sugar refinery beginning to manufacture paper from its own bagasse (sugarcane waste). Rather, Hypertherm's vertical integration is more about the development of internal capabilities around waste reduction, priming the company for its partnership with Casella. Casella, on the other hand, is already vertically integrated, at least in the Northeast, and is able to fit the CHRP into its existing collection and recycling networks. Again, the dual role that Casella plays as both an industrial actor and a facilitator (see below) weakens the applicability of this dynamic model. 


\subsection{Facilitation-Brokerage}

"Brokerage is a dynamic where a third-party organization steps in to make the potential market for secondary resources more transparent, to help it emerge or increase in terms of the quantity of exchange" ([12], p. 7).

The two facilitation dynamics have as their initial actor a "third-party organization", which in the CHRP is represented by Casella. The motivation for the initial actor in the brokerage dynamic is to "establish/increase transparency of market for firms to develop IS". This is accurate for Casella only insofar as the CHRP facility is always one of the participants in each linkage.

(1) A third-party organization sets up a brokerage system

Through its decades of experience in waste management and recycling, Casella has created an extensive network of 750+ recycling and reuse vendors, as well as a system for finding, qualifying, and managing new vendors.

(2) The broker establishes a market for industrial symbiosis development

Hypertherm and Casella create the CHRP facility, which brings together hard-to-recycle materials from around the Upper Valley region.

(3) Industrial actors engage and develop symbiotic exchanges through the market system.

Through the CHRP, businesses are able to recycle their small-volume or hard-to-recycle materials.

Although Casella certainly plays the role of a broker in the CHRP, it is a different kind of broker from, for example, the National Industrial Symbiosis Programme (NISP) [37] or the U.S. Business Council on Sustainable Development (USBCSD) [38], both of which facilitate but do not participate in the exchanges. This distinction might be why the CHRP does not exhibit what Boons et al. identify as a typical outcome from this model: a one-off network that struggles to maintain vitality over time.

\subsection{Facilitation-Collective Learning}

"Third parties ... may seek to initiate and maintain a process of collaborative learning, which they deem necessary to arrive at more structural and more advanced symbiotic linkages" ([12], p. 7).

Casella is again identified as the initial actor, and the motivation, "enabl[ing] firms to develop tacit knowledge," can be understood as enabling firms to recognize the value of resource management services.

(1) A facilitator picks up the concept of industrial symbiosis from existing examples

Casella learns about resource management from Ligon and A Greener Solution.

(2) The concept is translated into specific regional context

Effective resource management in the Upper Valley requires the accumulation of low-tonnage and hard-to-recycle materials from multiple small-to-medium sized firms.

(3) Industrial actor and facilitator engage in collaborative learning to develop symbiotic network.

Casella and Hypertherm collaborate to create the CHRP.

The specific actions in the collective learning model do not map well to the CHRP narrative, but the underlying concepts are nevertheless very well-represented. Tacit knowledge in the CHRP network includes those processes that each firm can employ to create higher value waste flows. The focus on collective learning also acknowledges the innovative nature of the CHRP, as well as how trust among key players enables continual collective learning and adaptation.

\subsection{Remaining Three Types}

The remaining dynamic types are not apparent in the CHRP. In all three dynamics-pilot facilitation and dissemination, government planning, and eco-cluster development-there is some 
top-down pressure (from a government, third party, or industrial actor) to replicate a model observed elsewhere in the world, which was not the case in the CHRP. So, although it may appear to exhibit qualities of, for example, an eco-cluster, the eponymous IS dynamic is not active, nor are the other two top-down dynamics.

\subsection{Proposed Dynamic: Active Facilitation}

In each of the four positively identified dynamics, there are characteristics that are well aligned with the CHRP narrative and others that seem unrepresentative. It is possible, and acceptable within the Boons et al. typology, for the CHRP to be some phase model of the four dynamics, switching from one to another, even before the first is completed. For example:

(1) Self-organization: The whole venture is started by an industrial actor, Hypertherm, pursuing economic and environmental benefits from finding reuse and recycling options for its wastes, and finds a partner in Casella.

(2) Facilitation — brokerage: Instead of acting solely as a direct exchange partner, Casella acts also as a broker, able to bring together multiple waste generators and reuse and recycling vendors.

(3) Organizational boundary change: Hypertherm and Casella both, in a way, expand their organizational boundaries to create a shared partnership activity and facility.

(4) Facilitation-collective learning: By participating in the CHRP, Hypertherm and other waste generators in the Upper Valley develop the capacity to create more and more value from their waste streams.

Although this is a reasonable, if incomplete, description of the CHRP narrative, it is highly inelegant. Instead of the dynamics adding up into clear phase models, they seem to be active simultaneously, with each more or less "dominant" depending on the actor's perspective. Phase models may yet emerge; the CHRP is only 2 years old.

Nevertheless, there are characteristics brought to light by the CHRP that are unaddressed by the existing seven Boons et al. types. In particular, none of the dynamics adequately make room for an organization that acts as both a node in the network and as a broker (in the IS dynamics definition of the term). Yet, this is how Casella behaves in the CHRP. Existing hub-and-spoke networks have an industrial actor at the hub. Having a broker serve that central function does not necessarily weaken the network. On the other hand, it potentially increases both flexibility and performance of the system, as the central actor has substantial waste recycling knowledge and capabilities. At this stage, it is unclear how important it is for this dynamic model, which we call "Active facilitation", to have the collaboration between a broker (Casella) and an industrial actor (Hypertherm), or if it would be sufficient for a broker to act alone. Nonetheless, this model seems to be promising, and might open up a large new body of examples for IS scholars to study.

\section{Discussion and Conclusions}

Boons et al. ask the question, "Are different dynamics triggered under specific conditions?" A single case study like this one is not enough to answer that question one way or another. Instead, we can make some conjectures about specific conditions and characteristics that appear to have been important for the emergence of the CHRP.

First, how important was the geographic region? The Upper Valley has a distinct industrial heritage and culture from the rest of the U.S. It may seem romantic and irrelevant to have started the case study with a description of the early industrial development of the region, but even today both the economic structure and the culture of the Upper Valley reflect certain qualities from that time. The industrial base, while smaller than it was 70 years ago, remains well-diversified and in proportion with the towns, that is to say, small scale and numerous. Industry in the region has not been consumed by bigness, and livability and commitment to the well-being of people appear to be commonly shared business values. In addition, the Yankee traditions of cooperation and ingenuity remain alive and well. 
The Hypertherm VP of CSR explicitly referenced the former when she first proposed bringing together waste generators throughout the region to increase waste volumes. The innovative organizational model embodied by the CHRP therefore fits well in the Upper Valley.

Second, how important were the key companies? It is difficult to imagine the specific sequence of events occurring with a company other than Hypertherm. The combination of lean manufacturing excellence, employee ownership, a strategic vision oriented on the long-term, and a serious commitment to zero waste goals is a unique one. All of the pieces were in place for the company to successfully interface with Casella, once their resource management capabilities were brought fully online. In addition to those capabilities, Casella's deep regional roots, extensive internal and external networks, and strategic orientation towards innovation in its customer solutions business made it not just an ideal but a necessary partner in the development of the CHRP.

Third, how important were individual people? In every innovative organization, there are individuals who can be credited with indispensability. In the case of the CHRP, there were a handful of people that truly did play a vital role by virtue of their expertise and leadership skills. Beyond specific individuals, however, it appears that relationships, even incidental ones, were important markers of success. Leaders from Hypertherm and Casella are both members of the NHBSR. Multiple executives at both companies, including some directly involved with the CHRP, received their MBAs from Dartmouth. One of Hypertherm's environmental managers went to the same elementary school as Casella's Hypertherm account manager. The mere existence of these cross-company relationships is itself a characteristic of both the companies and the region. The human scale of the business world in which the CHRP emerged helped to create a baseline level of trust and respect, which in turn contributed to a more positive working relationship. This echoes the long-held understanding of the importance of social capital and related concepts in successful models of IS [39].

In summary, the Casella-Hypertherm Recycling Partnership can be understood as a novel form of actively facilitated IS, in which a materials and waste management company (Casella) works closely with a primary industrial partner (Hypertherm) to find economically and environmentally beneficial uses for its wastes. This creates an opportunity for easy participation by secondary industrial partners and forms a hub-and-spoke network of IS. The Boons et al. typology of IS dynamics is potentially useful for understanding the formation of the CHRP, but is nevertheless demonstrated to be incomplete.

Acknowledgments: This research was supported by the Yale Center for Industrial Ecology. The author is deeply grateful to all of the interview subjects: Paul Ligon, Abbie Webb, Matt Albertazzi, B.J. Crowley, and Alex Poisson from Casella; and Jenny Levy, Robin Tindall, John Rooney, and Frank Austin from Hypertherm. Thank you to Paul Ligon, Abbie Webb, and Liza Casella for their help in facilitating this research and for their time and insight in reviewing this manuscript.

Conflicts of Interest: The authors declare no conflict of interest.

\section{References}

1. Chertow, M.R. Industrial Symbiosis: Literature and Taxonomy. Annu. Rev. Energy Environ. 2000, 25, 313-337. [CrossRef]

2. Hoffman, A.J.; Corbett, C.J.; Joglekar, N.; Wells, P. Industrial Ecology as a Source of Competitive Advantage. J. Ind. Ecol. 2014, 18, 597-602. [CrossRef]

3. Park, H.S.; Rene, E.R.; Choi, S.M.; Chiu, A.S.F. Strategies for Sustainable Development of Industrial Park in Ulsan, South Korea-From Spontaneous Evolution to Systematic Expansion of Industrial Symbiosis. J. Environ. Manag. 2008, 87, 1-13. [CrossRef] [PubMed]

4. Curran, T.; Williams, I.D. A Zero Waste Vision for Industrial Networks in Europe. J. Hazard. Mater. 2012, 207-208, 3-7. [CrossRef] [PubMed]

5. Schwarz, E.J.; Steininger, K.W. Implementing Nature's Lesson: The Industrial Recycling Network Enhancing Regional Development. J. Clean. Prod. 1997, 5, 47-56. [CrossRef]

6. Ehrenfeld, J.; Gertler, N. Industrial Ecology in Practice: The Evolution of Interdependence at Kalundborg. J. Ind. Ecol. 1997, 1, 67-79. [CrossRef] 
7. Chertow, M.R.; Lombardi, D.R. Quantifying Economic and Environmental Benefits of Co-located Firms. Environ. Sci. Technol. 2005, 39, 6535-6541. [CrossRef] [PubMed]

8. Jacobsen, N.B. Industrial Symbiosis in Kalundborg, Denmark: A Quantitative Assessment of Economic and Environmental Aspects. J. Ind. Ecol. 2006, 10, 239-255. [CrossRef]

9. Desrochers, P. Industrial Ecology and the Rediscovery of Inter-firm Recycling Linkages: Historical Evidence and Policy Implications. Ind. Corp. Chang. 2002, 11, 1031-1057. [CrossRef]

10. Desrochers, P. Cities and Industrial Symbiosis: Some Historical Perspectives and Policy Implications. J. Ind. Ecol. 2001, 5, 29-44. [CrossRef]

11. Chertow, M.R. “Uncovering” Industrial Symbiosis. J. Ind. Ecol. 2007, 11, 11-30. [CrossRef]

12. Boons, F.; Chertow, M.; Park, J.; Spekkink, W.; Shi, H. Industrial Symbiosis Dynamics and the Problem of Equivalence: Proposal for a Comparative Framework. J. Ind. Ecol.. [CrossRef]

13. Casella Waste Systems, Inc. Casella Waste Systems Honored Along with Its Customer Hypertherm for Innovative Recycling and Waste Reduction Partnership. Available online: https:/ /www.casella.com/sites / default/files/2016-12/news-release-nhbsr-award-casella.pdf (accessed on 23 November 2016).

14. Beihl, M. From Forest to Freshet: The Development of the Upper Connecticut River Valley of New Hampshire, 1750-1820. Honors Thesis, University of New Hampshire, Durham, NH, USA, 2012. Available online: http:/ / scholars.unh.edu/cgi/viewcontent.cgi?article=1031\&context=honors (accessed on 19 March 2017).

15. Brown, R.A. (Ed.) Where the Great River Rises: An Atlas of the Connecticut River Watershed in Vermont and New Hampshire; Dartmouth College Press: Hanover, NH, USA, 2009.

16. Brown, C. Industrial Revolution in the Upper Connecticut River Valley: An Overview; American Precision Museum: Windsor, VT, USA, 2007; Available online: https:/ /www.americanprecision.org/images/pdfs/ Mod_1_Introductory_essay.pdf (accessed on 5 January 2017).

17. Ewald, R.J.; Mulligan, A.D. Proud to Live Here in the Connecticut River Valley of Vermont and New Hampshire; Connecticut River Joint Commissions: Charlestown, NH, USA, 2003.

18. Haslach, R.; Leland, R. The Lebanon NH-VT Micropolitan Statistical Area: A Geo-Demographic Review. Available online: http://lebcity.net/Planning/Documents/studies/MicropolisStudy.pdf (accessed on 29 November 2016).

19. U.S. Census Bureau. American Community Survey, 2011-2015 American Community Survey 5-Year Estimates, Table B01003: Total Population. Available online: http://factfinder.census.gov/bkmk/ table/1.0/en/ACS/15_5YR/B01003/0400000US33.36000\T1\textbar\{\}0400000US50.36000 (accessed on 4 January 2017).

20. U.S. Census Bureau. American Community Survey, 2011-2015 American Community Survey 5-Year Estimates, Table C24050: Industry by Occupation for the Civilian Employed Population 16 Years and Over. Available online: http:/ / factfinder.census.gov/bkmk/table/1.0/en/ACS/15_5YR/C24050/0400000US33. $36000 \backslash \mathrm{T} 1 \backslash$ textbar\{\}0400000US50.36000 (accessed on 4 January 2017).

21. U.S. Census Bureau. County Business Patterns, 2015 Business Patterns, Table CB1500A13: Geography Area Series: County Business Patterns by Employment Size Class. Available online: http:/ / factfinder.census.gov/ bkmk/table/1.0/en/BP/2015/00A3/310M200US17200/naics 31-33\T1 \textbar\{\}ALL-L3-31-33 (accessed on 4 March 2017).

22. New Hampshire Employment Security; Economic and Labor Market Information Bureau. The Upper Valley-OnTheMap: A Profile of the Lebanon-Hanover NH-VT Micropolitan NECTA; New Hampshire Employment Security, Economic and Labor Market Information Bureau: Concord, NH, USA. Available online: https:/ / www.nhes.nh.gov/elmi/products/documents/upper-valley-onthemap.pdf (accessed on 3 January 2017).

23. Casella Waste Systems, Inc. 2015 Annual Report. 2016. Available online: http://ir.casella.com/annuals.cfm (accessed on 3 March 2017).

24. Ligon, P.; Mishra, P.N.; Votta, T. Waste service providers become resource managers. BioCycle 2000, 41, 51-54.

25. Halme, M.; Anttonen, M.; Kuisma, M.; Kontoniemi, N.; Heino, E. Business models for material efficiency services: Conceptualization and application. Ecol. Econ. 2007, 63, 126-137. [CrossRef]

26. ICF International National Association of Energy Services Companies. Introduction to Energy Performance Contracting. Available online: https://www.energystar.gov/ia/partners/spp_res/Introduction_to_ Performance_Contracting.pdf (accessed on 2 March 2017). 
27. Tukker, A. Eight types of product-service system: Eight ways to sustainability? Experiences from Suspronet. Bus. Strat. Env. 2004, 13, 246-260. [CrossRef]

28. Ligon, P.; Votta, T. Strategic contracting increases waste prevention and materials recycling. Resour. Recycl. 2001, 20, 33-45.

29. Casella Waste Systems, Inc. Becton, Dickinson and Company (BD) Case Study. Available online: https:/ / www.casella.com/case-studies/becton-dickinson-and-company-bd-case-study (accessed on 12 November 2016).

30. Hypertherm Inc. Hypertherm's Mission. Available online: https://www.hypertherm.com/en-US/ourcompany/about-us/vision-and-culture/ (accessed on 7 January 2016).

31. Koller, F. Spark: How Old-Fashioned Values Drive a Twenty-First Century Corporation; PublicAffairs: New York, NY, USA, 2010.

32. Sanders, B. Q\&A with Hypertherm's Dick and Barbara Couch. New Hampshire Business Review. 4 April 2014. Available online: http:/ / www.nhbr.com/April-4-2014/Q-A-with-Hypertherms-Dick-and-Barbara-Couch/ (accessed on 17 January 2017).

33. Hypertherm. Corporate Social Responsibility, 2015 Annual Report. 2016. Available online: https:// www.hypertherm.com/en-US/our-company/corporate-social-responsibility/csr-reports/ (accessed on 10 December 2016).

34. Rajala, L. Zeroing in on no waste: Hypertherm reaps benefits from recycling. New Hampshire Business Review. 10 July 2015. Available online: http:/ / www.nhbr.com/July-10-2015/Zeroing-in-on-no-waste/ (accessed on 25 October 2016).

35. Lippman, J. Hypertherm, Casella work to maximize recycling. Upper Valley Business News. 24 May 2015. Available online: http://enterprise.vnews.com/2015/05/24/hypertherm-casella-work-to-maximizerecycling/ (accessed on 25 October 2016).

36. Henderson, G. Program takes aim at industrial waste issue. Business Vermont. 10 June 2016. Available online: http:/ / www.businessvermont.com/program-takes-aim-at-industrial-waste-issue/ (accessed on 25 October 2016).

37. Mirata, M. Experiences from early stages of a national industrial symbiosis programme in the UK: determinants and coordination challenges. J. Clean. Prod. 2004, 12, 967-983. [CrossRef]

38. Mangan, A.; Olivetti, E. By-product synergy networks: Driving innovation through waste reduction and carbon mitigation. In Sustainable Development in the Process Industries: Cases and Impact; Harmsen, J., Powell, J.B., Eds.; AIChE and Wiley: Hoboken, NJ, USA, 2010; pp. 81-108.

39. Ashton, W.S.; Bain, A.C. Assessing the "Short Mental Distance" in Eco-Industrial Networks. J. Ind. Ecol. 2012, 16, 70-82. [CrossRef]

(C) 2017 by the author. Licensee MDPI, Basel, Switzerland. This article is an open access article distributed under the terms and conditions of the Creative Commons Attribution (CC BY) license (http://creativecommons.org/licenses/by/4.0/). 